\title{
Risk Assessment for Patients with Chronic Respiratory Conditions in the Context of the SARS-CoV-2 Pandemic Statement of the German Respiratory Society with the Support of the German Association of Chest Physicians
}

\author{
Marek Lommatzsch ${ }^{a}$ Klaus F. Rabe ${ }^{b}$ Christian Taube $^{c}$ Marcus Joest $^{d}$ Michael Kreuter $^{\mathrm{e}}$ \\ Hubert Wirtz ${ }^{f}$ Torsten Gerriet Blum ${ }^{g}$ Martin Kolditz ${ }^{\text {h }}$ Hilte Geerdes-Fenge ${ }^{a}$ \\ Ralf Otto-Knapp ${ }^{i}$ Brit Häcker ${ }^{i}$ Tom Schaberg $^{j}$ Felix C. Ringshausen ${ }^{k}$ Claus F. Vogelmeier ${ }^{l}$ \\ Niels Reinmuth ${ }^{m} \quad$ Martin Reck $^{\mathrm{b}}$ Jens Gottlieb ${ }^{k} \quad$ Stavros Konstantinides $^{\mathrm{n}} \quad$ Joachim Meyer $^{\circ}$ \\ Heinrich Worth $^{p}$ Wolfram Windisch ${ }^{q}$ Tobias Welte ${ }^{k}$ Torsten Bauer $^{\mathrm{g}}$

\begin{abstract}
aDepartment of Pneumology, University of Rostock, Rostock, Germany; 'bungenClinic Großhansdorf, Großhansdorf,

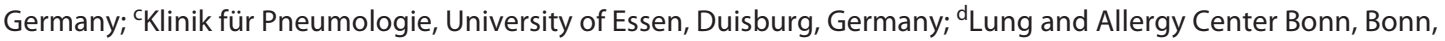

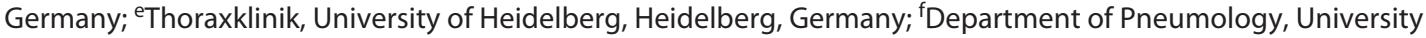
of Leipzig, Leipzig, Germany; ${ }^{2} L u n g$ Hospital Heckeshorn, Helios Klinikum Emil von Behring, Berlin, Germany; hDepartment of Pneumology, University of Dresden, Dresden, Germany; 'German Central Committee against Tuberculosis, DZK, Berlin, Germany; ${ }^{j}$ Rothenburg, Germany; ${ }^{k}$ Department of Respiratory Medicine, University of Hannover, Hanover, Germany; 'Department of Medicine, Pulmonary and Critical Care Medicine, University of Marburg, Marburg, Germany; ${ }^{\mathrm{m} C l i n i c}$ Munich-Gauting, Munich, Germany; ${ }^{\text {} U n i v e r s i t y ~ o f ~ M a i n z, ~ M a i n z, ~ G e r m a n y ; ~}$ 'Lung Center Bogenhausen and Harlaching, Hospital Munich, Munich, Germany; ${ }^{p}$ Fürth, Germany; ${ }^{9}$ Hospital for Lung Diseases, Köln-Merheim, Cologne, Germany
\end{abstract}

\section{Keywords}

SARS-CoV-2 · COVID-19 $\cdot$ Risk assessment $\cdot$ Respiratory diseases

\begin{abstract}
Assessing the risk for specific patient groups to suffer from severe courses of COVID-19 is of major importance in the current SARS-CoV-2 pandemic. This review focusses on the risk for specific patient groups with chronic respiratory conditions, such as patients with asthma, chronic obstructive pulmonary disease, cystic fibrosis (CF), sarcoidosis, interstitial lung diseases, lung cancer, sleep apnea, tuberculosis, neuromuscular diseases, a history of pulmonary embolism,
\end{abstract}

and patients with lung transplants. Evidence and recommendations are detailed in exemplary cases. While some patient groups with chronic respiratory conditions have an increased risk for severe courses of COVID-19, an increasing number of studies confirm that asthma is not a risk factor for severe COVID-19. However, other risk factors such as higher age, obesity, male gender, diabetes, cardiovascular diseases, chronic kidney or liver disease, cerebrovascular and neurological disease, and various immunodeficiencies or treatments with immunosuppressants need to be taken into account when assessing the risk for severe COVID-19 in patients with chronic respiratory diseases.

(c) 2022 The Author(s).

Published by S. Karger AG, Basel karger@karger.com www.karger.com/res

Karger $\stackrel{\text { ' }}{5}$

BOPEN ACCESS
(C) 2022 The Author(s)

Published by S. Karger AG, Basel

This is an Open Access article licensed under the Creative Common Attribution-NonCommercial-4.0 International License (CC BY-NC) (http://www.karger.com/Services/OpenAccessLicense), applicable to the online version of the article only. Usage and distribution for commercial purposes requires written permission.
Correspondence to:

Marek Lommatzsch, marek.lommatzsch@med.uni-rostock.de Michael Kreuter, kreuter@uni-heidelberg.de 


\section{Introduction}

The current SARS-CoV-2 pandemic has created uncertainty regarding the question of how to adequately protect specific patient groups suffering from chronic respiratory conditions - both among physicians, who have a duty to provide patients with suitable and meaningful protective measures and among patients, who understandably wish to protect themselves optimally against COVID-19. Assessing the risk for specific patient groups is therefore of particular importance.

\section{Characteristics of the Disease}

The SARS-CoV-2 virus responsible for COVID-19 can be transmitted also by asymptomatic carriers (according to current estimates, $15-31 \%$ of all infected persons remain asymptomatic) $[1,2]$ or by those infected before they develop symptoms [3] (Fig. 1). This, in addition to the high contagiousness, contributes to the rapid spread of the virus. Most COVID-19 cases are mild to moderate (Fig. 1), and patients are symptomatic for an average of 11.5 days (the most common symptoms are: cough, fever, loss of smell and taste, fatigue, and myalgia; gastrointestinal symptoms are also possible in some patients) [4, 5]. A minority of patients develops severe COVID-19 7-10 days after the onset of symptoms (Fig. 1) [4], with shortness of breath, pneumonia, and respiratory distress, which, in less than $25 \%$ of hospitalized patients [6], requires intensive care (including mechanical ventilation) $[7,8]$. Signs of progression to severe disease are shortness of breath, tachypnea, and/or drop in oxygen saturation below 94\% [5]. In addition to pneumonia, severe COVID-19 can result in severe endothelial injury of the pulmonary vessels [9] with intravascular thrombosis and thromboembolic events [10,11], massive release of cytokines [12], and multi-organ failure [4].

\section{Epidemiology of Severe Courses of the Disease}

Most recent data based on reports of the Robert Koch Institute (RKI) in Germany show a hospitalization rate of $10 \%$ and case fatality rates between 2 and $4 \%$ ( $89 \%$ of the deceased were at least 70 years old) [2]. In an evaluation based on the health insurance data of 10,021 patients in 920 hospitals in Germany, 17\% of patients received mechanical ventilation, their median age was 71 , and $66 \%$ were male. Inhospital mortality was $22 \%$ (16\% of the nonventilated and $53 \%$ of the ventilated patients) [6]. Based on a comparable analysis of health insurance data, this inhospital mortality is higher than in patients with community-acquired pneumonia (17\%) [13]. The real mortality of COVID-19 is still unknown as it depends on the actual number of those infected, which is unknown. Current models from Europe assume a mortality rate of between $0.3 \%$ and $0.9 \%$ [14-17]. Hence, the mortality rate in the current SARS-CoV-2 pandemic seems to be higher than that for seasonal influenza during a severe season $(0.1 \%)$ [18]. However, in contrast to SARS-CoV-2, only direct deaths are considered as influenza-related deaths in patients infected with influenza viruses.

The following statements refer, in particular, to the risk of severe disease or death after SARS-CoV-2 infection (Fig. 1). They provide answers to frequently asked questions based on 13 exemplary cases.

\section{Question 1 (general): Who is most at risk for a severe course of COVID-19?}

Answer 1: Current data show that higher age is the most significant risk factor for severe COVID-19 or death. The mortality risk increases continuously from the 6th decade of life and is 20 times higher for an 80-year-old person than for a 50 -year-old person [19]. This is also confirmed by data from Germany: while persons $\geq 70$ years of age were only $16 \%$ of those infected, $89 \%$ of deaths occurred in this age-group [2]. Additional established risk factors for severe COVID-19 progressions, according to current knowledge, are: [6, 19-26]

- obesity

- male gender

- diabetes mellitus

- cardiovascular diseases

Other risk factors for severe COVID-19, according to current knowledge, also include: [6, 19-26]

- chronic kidney or liver disease

- cerebrovascular/neurological diseases

- cancer

- COPD

- advanced interstitial lung disease (ILD)

- immunodeficiency/treatment with immunosuppressants

The presence of more than one chronic disease or more than one risk factor significantly increases the risk of severe disease $[23,27]$. The mortality risk is particularly high for nursing home residents because of their advanced age and high prevalence of multiple chronic diseases. In addition, the virus is easily transmitted in nursing homes as nursing staff care for multiple residents with close physical contact [28]. 


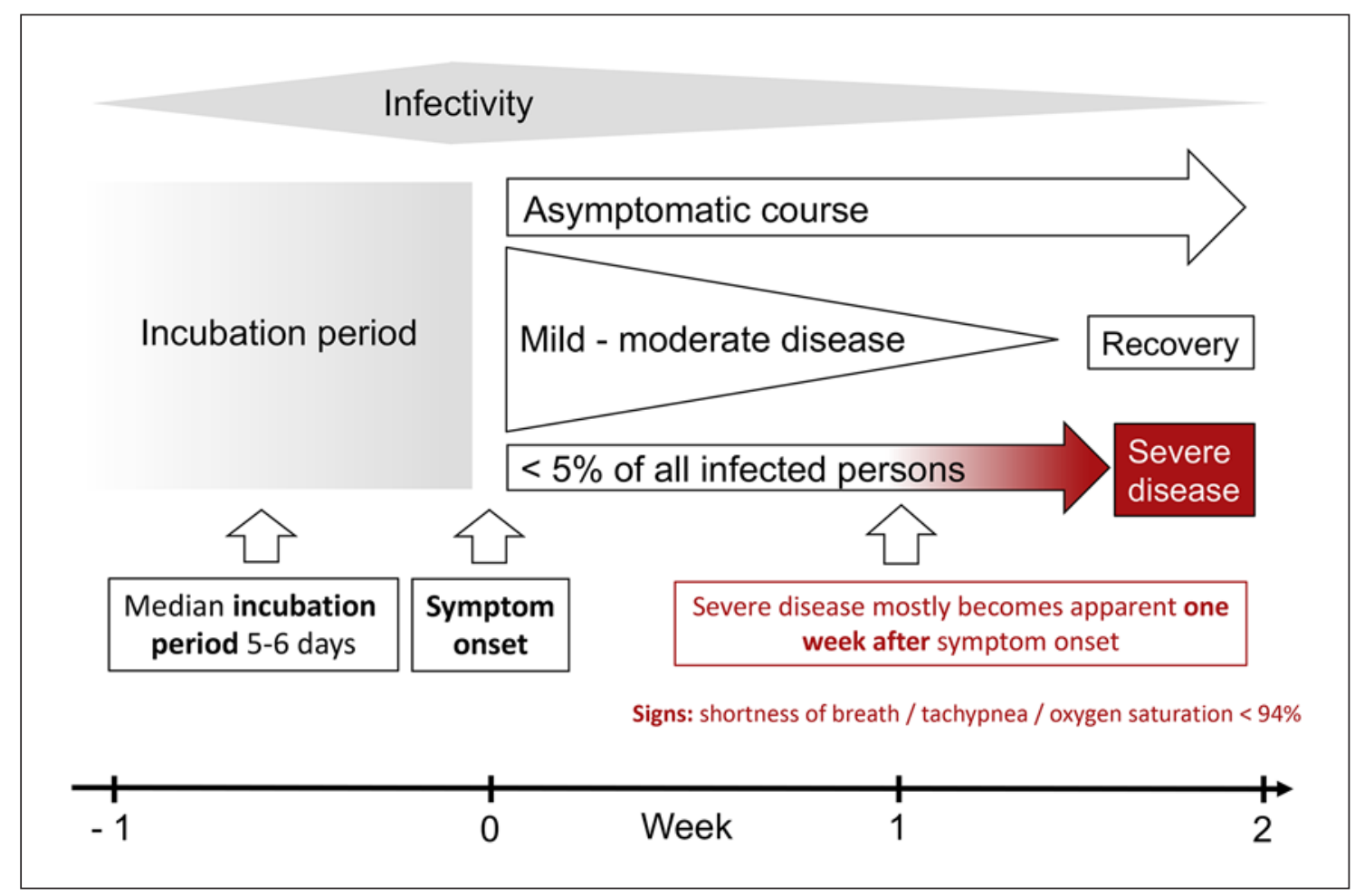

Fig. 1. Courses of SARS-CoV-2 infections. With a median incubation period of 5-6 days, SARS-CoV-2 has a longer incubation period than the influenza virus, but the risk of transmission from one person to another is higher. In addition, most infected have mild symptoms or are asymptomatic. During this incubation period or during a mild or asymptomatic course of the disease, those infected with SARS-CoV-2 can therefore spread the virus quickly and unnoticeably, with virus transmission peaking around the day of onset of

\section{Question 2 (mild to moderate asthma): I am a 58-year-old teacher and have moderate, well- controlled asthma; I regularly use my inhaled medications. Does this make me a risk patient? Is it safe for me to go to work during the coronavirus pandemic?}

Answer 2: Early general COVID-19 case series indicated that having asthma does not increase the risk for severe COVID-19 [6, 19-26]. Subsequently, specific case series which included only patients with asthma from Spain [29], Belgium [30], France [31], Brazil [32], Russia [33], Japan [34], and the USA [35-40] unanimously confirmed that asthma is not a risk factor for severe COVID-19 [41]. Even patients with severe asthma treated with biologics do not appear to be at an increased risk [42-49]. One study from Korea suggested that the subgroup of patients with nonallergic asthma might have an increased symptoms. In contrast to severe influenza-related pneumonia, severe courses of COVID-19 rarely cause an abrupt deterioration of the patient's general condition after the incubation period. On average, it is only after 1 week of relatively mild symptoms that shortness of breath and respiratory distress may appear (only in very few cases, a rapid deterioration can occur directly after symptom onset). Signs of progression to severe disease are shortness of breath, tachypnea, and/or a drop in oxygen saturation below $94 \%[4,5]$. from Korea showed asthma not to be an independent risk factor for severe COVID-19 in Korea [51]. Based on the large number of data available today, it can be assumed that asthma (of all severities) is not an independent risk factor for severe COVID-19 [52]. There are even speculations that this risk may be lower in asthma [53-55], in part due to a reduced expression of the ACE-2 receptor responsible for the uptake of SARS-CoV-2 in the airways [56]. This was observed, in particular, in patients with allergies and/or type 2 inflammation [57-60]. Currently, there is also no evidence that treatment with low- or medium-dose inhaled corticosteroids (ICSs) to treat asthma increases the risk of developing severe COVID-19 [61]. Since ICS generally reduce the risk of asthma exacerbations and may additionally reduce the expression of the ACE-2 receptor in the airways [62], a protective effect is instead suspected [63]. Discontinuation of ICS therapy 
may lead to severe asthma exacerbations and contribute to a severe course of the disease in the event of a SARS-CoV-2 infection. Therefore, inhalation therapy, and in particular with ICS, should be continued in patients with well-controlled asthma during the SARS-CoV-2 pandemic: there are separate and detailed statements on this topic by the DGP (statement on asthma therapy with ICSs, www.pneumologie.de) and by the GINA (https://ginasthma.org/recommendations-for-inhaled-asthma-controller-medications). Allergen immunotherapy (allergen-specific immunotherapy) should also be continued: A separate EAACI statement is available in this regard [64]. We therefore suggest that patients with asthma who have no acute symptoms and no COVID-19-relevant comorbidities can work in schools as long as the RKI-recommended hygiene measures (AHA-L rules of physical distancing and hygiene: keep physical distance, observe hygiene procedures, wear a face mask, ventilate indoor areas) are observed.

\section{Question 3 (severe asthma): I am an executive, 48 years old, and have severe asthma. I am using several inhaled medications in high doses, and receive a biologic regularly (the injections are performed by my respiratory physician). Can I continue to work at my job? Should I self-isolate at home? Should I inject the biologic myself at home?}

Answer 3: Currently, there is no evidence that patients using biologics would generally be at a higher risk of developing severe COVID-19 $[65,66]$. Patients with severe asthma treated with biologics do not appear to be at an increased risk of a severe disease [42-49]. The only published patient with severe asthma under biologic therapy who died of COVID-19 had 4 typical COVID-19 risk factors (age, male gender, hypertension, and diabetes), which explained the severe course of the disease [29]. However, there is evidence that treatment with systemic steroids [19] or high-dose ICS [61] (which can be equivalent to a low-dose therapy with systemic steroids [67]) may increase the risk of severe COVID-19. In patients with severe asthma, it is therefore of particular importance during the coronavirus pandemic to avoid longterm or repeated systemic steroid therapy, by following a guideline-based therapy, for example, with biologics. It is therefore recommended to continue the biologic therapy in patients with severe asthma, especially to avoid the necessity of systemic corticosteroid therapy and/or exacerbation-related hospitalizations. A separate DGAKI statement on this topic is available (https://dgaki.de/ biologika-therapie-u-covid-19). Patients with wellcontrolled severe asthma, without acute symptoms, can work outside their homes, as long as the RKI-recommended behavioral measures (AHA-L rules of physical distancing and hygiene) are strictly observed. Self-administration of a biologic at home (which is possible and approved for omalizumab, mepolizumab, benralizumab, and dupilumab) should be encouraged to reduce contact with medical facilities and thus minimize the risk of contact with patients infected with SARS-CoV-2.

\section{Question 4 (COPD): I am a 68-year-old pensioner with COPD. I had a heart attack 3 years ago, and I suffer from high blood pressure. Currently, I still smoke 3-4 cigarettes per day. Can I continue to take my high blood pressure medication (e.g., ramipril) and continue with inhalations? Should I be vaccinated against pneumococci? Should I shelter at home for the duration of the coronavirus pandemic? Can I see my children and grandchildren?}

Answer 4: According to current data, COPD patients are at a moderately increased risk of severe COVID-19 $[22,26,68]$. Patients with COPD and cardiovascular comorbidities are at a significantly increased risk [22, 69]. Inhalation therapy according to current guidelines should generally be continued. So far, there is no evidence that ICSs might negatively impact the prognosis of patients with COPD. A study of almost 150,000 patients with COPD from the UK suggested an increased mortality in patients with COPD treated with ICS. However, the authors concluded that this was probably the result of patient selection (bias by indication) rather than treatment [61]. High blood pressure therapy, including ACE inhibitors (such as ramipril) or sartans, should be continued; there is no evidence that these drugs increase the risk of severe disease [70, 71]. It is strongly recommended to stop smoking cigarettes. Vaccination against pneumococci is also strongly recommended, if not already done. As long as there are no signs of COVID-19 disease, sheltering at home is unnecessary. However, the RKI recommendations (AHA-L rules of physical distancing and hygiene) should be strictly observed. In the current situation, get-togethers with children or grandchildren should be avoided as much as possible, and keeping in touch over the phone or by video conference should be preferred. 
Question 5 (cystic fibrosis): I am a 22-yearold student and have cystic fibrosis. I take my medication regularly and have been receiving treatment at a cystic fibrosis outpatient clinic since I was a child. Should I keep my current appointments with my physiotherapist? Should I stay at home for the duration of the coronavirus pandemic? Should I continue to take my medication as before and also continue the inhalation therapy?

Answer 5: The published number of COVID-19 cases in patients with cystic fibrosis (CF) continues to be very limited [72]. An update published by the "Cystic Fibrosis Registry Global Harmonization Group" reports 181 cases with SARS-CoV-2 from 19 countries in which approximately 85,000 CF patients reside (update: June 13, 2020) [73]. Among the infected patients, there were 32 transplanted patients (mostly status post lung transplant). A total of 11 (of which 7 were transplanted) patients required intensive care: 7 (of which 3 were transplanted) patients died. The authors conclude that a severe course was associated with increased age, $\mathrm{CF}$-associated diabetes, poorer lung function, and status post organ transplant [73]. Although $46 \%$ of the included patients were hospitalized and 23\% required supplemental oxygen, the course of the disease in this cohort was better than expected and more favorable than in other cohorts of patients with chronic lung diseases, which may be related to the protective effect of the relatively young age of CF patients [73]. In addition, these patients generally also practice very good basic hygiene, regardless of the SARS-CoV-2 pandemic. However, due to the fact that patients with $\mathrm{CF}$ in general have a significant increased risk for hospitalization, multiple comorbidities as well as a considerably shortened life expectancy compared to peers, immunization against SARS-CoV-2 is strongly encouraged and accordingly CF was explicitly included as a disease justifying immunization against SARS-CoV-2 with high priority in Germany. It is generally recommended that patients with CF or bronchiectasis of other etiology continue their primary therapy including pharmaceutic and nonpharmaceutic measures. This also applies to chest physiotherapy, which should be performed alone by the patient, whenever possible. Separate DGP recommendations are available on hygiene measures during the SARS-CoV-2 pandemic in connection with outpatient chest physiotherapy [74]. Many therapists offer treatment by video sessions in addition or as an alternative to in-person visits and have been permitted to re-

Risk Assessment in the SARS-CoV-2 Pandemic quest reimbursement for these therapies in Germany. Likewise, clinically indicated outpatient or inpatient antibiotic therapies and regular follow-ups at specialized outpatient centers should be continued. Close monitoring of laboratory parameters and clinical follow-ups are mandatory when starting CFTR modulator therapy (after week 2 and 6 and every 12 weeks thereafter in the first year of therapy) [75]. If initiation of a CFTR modulator therapy is already planned, the inherent risk of regular visits to CF outpatient centers (which in Germany usually follow very high hygiene standards) should be weighed against the benefit of an often significantly improved lung function and a lower exacerbation rate [76]. It is unnecessary for patients who show no signs of COVID-19 to stay at home permanently (and this is also not reasonable considering the many positive aspects of physical exercise). However, the RKI's behavioral recommendations (AHA-L rules of physical distancing and hygiene) should be strictly observed. In summary, the potential damage caused by failing to adhere to the CF-specific routine measures according to European standards of CF care appears to be greater than the potential damage caused by $\mathrm{CO}$ VID-19.

\section{Question 6 (interstitial lung disease): I am a 72-year-old pensioner with interstitial lung disease associated with rheumatoid arthritis. I regularly take methotrexate (15 mg/week) and prednisolone ( $5 \mathrm{mg} /$ day). I am on long-term oxygen therapy ( $2 \mathrm{~L}$ of $\mathrm{O}_{2} / \mathrm{min}$, administered via nasal cannula). Should I even dare leave the house during the coronavirus pandemic? Should I keep taking my medication? Should I continue oxygen therapy?}

Answer 6: ILD, especially pulmonary fibrosis, is believed to be associated with a higher risk of severe COVID-19. If hospitalization becomes necessary, ILD patients are at a significantly increased risk for severe COVID disease [77]. This is especially true for patients with idiopathic pulmonary fibrosis (IPF), particularly those with advanced disease stages or obesity. Even though there are limited data available, it should be considered that a temporary suspension of an otherwise indicated immunosuppressive therapy is associated with the risk of a worsening of the underlying condition (which will then require even higher doses of immunosuppressive therapy). The indication for immunosuppression should be reviewed in all types of ILD (includ- 
ing sarcoidosis) [78] treated by immunosuppressive therapy. If a continuation of the therapy is indicated, it should be continued without modification at the lowest possible dose. Only if the patient or a household member tests positive for SARS-CoV-2, immunomodulators such as azathioprine or methotrexate should be discontinued temporarily (in accordance with the DGRh recommendations, see www.dgrh.de) until clinical improvement is achieved. A prednisolone therapy should be continued at the lowest possible dose. Since antifibrotic agents in IPF or IPF-like behaving diseases protect against acute exacerbations that may develop in ILD in the context of a viral infection, this therapy should be continued. It is unnecessary for patients who show no signs of COVID-19 to stay at home permanently (and this is also not reasonable considering the many positive aspects of physical exercise). However, the RKI's behavioral recommendations (AHA-L rules of physical distancing and hygiene) should be strictly followed. Oxygen therapy should be continued without modification. There is still insufficient data regarding the nature, prognosis, and therapy of COVID-19-induced ILD. Studies are currently being conducted in this regard. Whether an antifibrotic or steroid therapy might be useful in these cases needs to be determined [79].

\section{Question 7 (sarcoidosis): I am 43 years old, not overweight, and have always been a nonsmoker. Two years ago, I was diagnosed with sarcoidosis with moderate lung and lymph node involvement. No other organ is affected. My lung function is normal. So far, I do not have to take medication to treat my sarcoidosis. Am I at a higher risk for severe COVID-19? Can I continue to go to work during the pandemic? What if my sarcoidosis worsens and I have to start taking regular medication? And can COVID-19 make my sarcoidosis worse?}

Answer 7: In a study from New York, sarcoidosis was not an independent risk factor for severe COVID-19. The risk was however increased in patients with moderately or severely impaired lung function [80]. An international registry study on 600 COVID-19 patients suffering from chronic inflammatory systemic diseases (including 10 patients with sarcoidosis) identified a higher risk of hospitalization for patients on glucocorticoid therapy receiving treatment with $\geq 10 \mathrm{mg}$ prednisolone equivalent per day, but not for patients on bi- ologics, DMARDs, or NSAIDs [81] (in a subsequent analysis, the authors identified no risk of severe disease progression in 41 sarcoidosis patients in relation to the glucocorticoid therapy) [82]. Two monocentric, sarcoidosis-specific observational studies detected proven COVID-19 infections in 5 (out of 238) and 10 (out of approximately 1,000$)$ patients with sarcoidosis, respectively. Clinical courses were favorable: only 2 patients were hospitalized, one of these 2 patients (with cardiac sarcoidosis, and no immunosuppressive medication prior to infection) died due to pulmonary embolism $[83,84]$. Likewise, 2 survey-based studies yielded low COVID-19 infection rates in a large international cohort of sarcoidosis patients [85] and a mixed regional Italian patient cohort with rheumatic diseases/sarcoidosis treated with biologics/DMARDs [86] (a reporting bias cannot be excluded in these studies). The key factors regarding the risk for patients with sarcoidosis are: (1) impaired lung function, (2) extrapulmonary organ involvement, (3) comorbidities, and (4) ongoing immunosuppressive therapy. In accordance with the recommendations of the European League Against Rheumatism (EULAR) and of the German Society of Rheumatology (DGRh) (www.dgrh.de), regarding the treatment of rheumatic conditions as well as the sarcoidosis-specific recommendations of an international panel of sarcoidosis experts, we recommend continuing immunosuppressive or immunomodulatory therapy at the lowest effective dose in patients with clinically stable sarcoidosis who do not have COVID-19. However, the indication for a therapy should be subject to a strict review. These patients can also continue to go to work as long as the RKI's behavioral recommendations (AHA-L rules of physical distancing and hygiene) are observed. In patients with active disease or impending organ complications, the initiation/continuation of immunosuppressive or immunomodulatory therapy should be carefully assessed under risk-benefit aspects. In most cases however it should be initiated or continued. In patients with sarcoidosis and acute COVID-19 disease, immunosuppressive or immunomodulatory sarcoidosis therapy should be suspended. If the decision is made to continue prednisolone, the therapy should be reduced to the lowest possible effective maintenance dose. This does not affect the indication and timing of a COVID-19-specific dexamethasone therapy $[78,87]$ 


\section{Question 8 (lung transplant): I am 53 years old and received a bilateral lung transplant 3 years ago. I regularly take numerous medications and pay close attention to all recommendations regarding my diet and lifestyle. Can I leave the house during the coronavirus pandemic? Should I continue taking all these medications as before?}

Answer 8: To date, there is no published data indicating that lung transplant patients are infected more frequently with SARS-CoV-2. The risk of severe COVID-19 in patients with lung transplants appears to be increased due to the required immunosuppression therapy. On the other hand, in vitro data for ciclosporine and tacrolimus indicate that both drugs have an inhibitory effect on virus replication. Several case series on patients with lung transplants with COVID-19 have been published so far. The first case published worldwide was of a German patient with COVID-19 after lung transplantion who had a moderate course [88]. In a large US multicenter cohort study including 482 organ transplant patients with COVID-19 (of which 30 were lung transplants), $78 \%$ of patients were hospitalized, $31 \%$ were intubated, and $21 \%$ died [89]. In other case series of transplant patients who had COVID-19 (which did not include patients with lung transplants) $25-28 \%$ of those infected died [90-92], including 2 patients who were not initially thought to require hospitalization [90]. Therefore, increased attention is required for transplant patients on days 7-10 after symptom onset, even if the clinical symptoms are initially mild (Fig. 1). A prophylactic adjustment of the immunosuppressive therapy is not recommended in the context of the coronavirus pandemic, and this is also not generally recommended for lung transplanted patients with SARS-CoV-2. Only in case of COVID-19, a temporary discontinuation of mycophenolate mofetil, sirolimus/ everolimus, and azathioprine within a triple drug regimen is recommended under close inhospital monitoring. Interactions of immunosuppressants, antivirals, and additional medication administered to treat COVID-19 need to be considered when treating patients after lung transplantation. It is unnecessary for these patients to stay at home permanently (and this is also not reasonable considering the many positive aspects of physical exercise). However, the RKI's behavioral recommendations (AHA$\mathrm{L}$ rules of physical distancing and hygiene) should be strictly observed. Patients with lung transplants should wear FFP-2 masks used for personal protection in special risk situations if pulmonary function is not significantly impaired.

Risk Assessment in the SARS-CoV-2 Pandemic
Question 9 (lung cancer): I am a pensioner. I am 71 years old and have lung cancer. I am currently undergoing chemotherapy as an outpatient. One bone metastasis was treated with radiation therapy 3 months ago; the treatment of another is pending. Should chemotherapy be continued during the current coronavirus pandemic? Should radiation therapy take place? May my children visit me?

Answer 9: Based on current knowledge, cancer patients, in general, are at a higher risk of developing severe COVID-19 [93-98]. Data on the course of the infection from over 1,000 patients with COVID-19 have been collected in a major international scientific database (TERAVOLT: http://teravolt-consortium.org) [99, 100]. A first analysis of this database shows that severe COVID-19 courses $(32 \%$ of patients recorded in the database died from COVID-19) are associated with factors such as poor general health (the most significant risk factor), advanced age, glucocorticoid therapy, current smoking, advanced disease stage, and the type of therapy [101, 102]. These risk factors were confirmed by evaluating 105 SARS$\mathrm{CoV}$-2-infected patients with lung cancer from New York (in this case series, $62 \%$ of the patients were hospitalized, $25 \%$ of the patients died) [103]. On the other hand, it was hypothesized that, in some patients, immunosuppression as part of the cancer therapy might prevent the massive cytokine release typical of severe COVID-19 and thus counteract progression to a severe disease state [104]. Due to the many different subtypes of cancer, cancer stages, therapies and prognoses, and the range of lung cancer types, a risk assessment and recommendation can only be made on a case-by-case basis. In general, surgeries, systemic therapies, or radiotherapy are vital for patients and should therefore neither be postponed nor canceled [105]. Moreover, local (e.g., DGHO, www.dgho.de) and global organizations such as ASCO (www.asco.org) and ESMO (www.esmo.org) have issued separate recommendations for the treatment of cancer in the context of the SARS-CoV-2 pandemic, with the latter providing highly specific, hierarchically structured recommendations (3 graded levels) for diagnostics and all types of local/systemic tumor therapies in lung cancer. In addition, detailed recommendations for the treatment, diagnosis, and management of patients with lung cancer and other malignant diseases were developed and discussed in an ESMO consensus statement [106]. The RKI's behavioral recommendations (rules of physical distancing and hygiene) also apply for patients with lung cancer and should also be strictly observed by all visitors. Regarding contact

Respiration 2022;101:307-320 
restrictions, the decision whether visits by relatives or friends should be allowed should be made on a case-bycase basis depending on the patient's prognosis; a general ban on visits is not appropriate.

\section{Question 10 (sleep apnea syndrome): I am 74 years old and weigh $120 \mathrm{~kg}$. I never smoked and, apart from high blood pressure, have no other conditions. In the past, I used to feel extremely exhausted when I woke up in the morning and was very tired during the day. Since regularly using my CPAP therapy, I feel refreshed when I wake up in the morning and am able to work in my garden all day. Do I belong to a high-risk group for severe coronavirus disease? Will I soon be able to host a barbecue party in my garden again?}

Answer 10: For patients with obstructive sleep apnea syndrome who need to use CPAP therapy every night, an increased risk can neither be excluded nor confirmed based on currently available data. In addition, a statement issued by the German Sleep Society (DGSM) notes that there is no conclusive evidence on whether CPAP therapy may worsen a COVID-19 infection: The therapy should therefore be continued [107]. However, the combination of obesity and arterial hypertension is generally associated with an increased risk of severe COVID-19 [6, 1926]. The RKI's behavioral recommendations (rules of physical distancing and hygiene) should therefore be strictly observed, and parties or social gatherings with friends should be avoided for the time being. The coronavirus pandemic should also be seen as an opportunity to tackle weight reduction, which offers many benefits in every respect.

\section{Question 11 (neuromuscular disease): I am 62 years old and suffer from a rare neuronal disease. I require ventilation via a mask every night because my respiration at night does not supply my lungs with sufficient oxygen. If I had coronavirus, would I even stand a chance of recovering and having my previous life back? Maybe I shouldn't even allow being placed in an intensive care unit at all?}

Answer 11: Patients with neuromuscular diseases who require noninvasive ventilation (NIV) suffer from a severe ventilatory insufficiency. Although epidemiological data in the context of the SARS-CoV-2 pandemic are not yet available for this patient group, a significantly increased risk of severe COVID-19 must be assumed as these patients lack ventilatory compensation capacity in COVID-19 pneumonia. Therefore, these patients may need to be intubated earlier as long as no therapy goal restrictions apply. On the other hand, a transfer to the intensive care unit does not necessarily have to involve intubation. A graduated concept can be applied in this case, including alternating oxygen administration via nasal high-flow and intensified noninvasive ventilation to avoid intubation $[8,108]$. In the case of invasive ventilation, significant problems can be expected when weaning these patients from the respirator. This further impacts their prognosis, even if ventilation in intensive care is primarily successful [109]. These patients' quality of life may already be reduced by the underlying condition and may even be further impaired after suffering an extended period of COVID-19 pneumonia. This should be discussed in detail on a caseby-case basis [110]. Patients should be encouraged to draw up a comprehensive and specific advance directive after consultation with their attending respiratory physician and after careful consideration.

\section{Question 12 (tuberculosis): I am 43 years old and had pulmonary tuberculosis 20 years ago. The condition was treated over 6 months with a combination of several pills. Several X-ray images of my lungs were taken afterwards, and my doctors confirmed that the tuberculosis has healed without sequelae. I have had no symptoms since then. Does this history make me a patient at risk for severe COVID-19? Would I be a patient at risk if I were currently taking tuberculosis medication?}

Answer 12: There is little data on SARS-CoV-2 infections in patients who have recovered from tuberculosis. The likelihood of developing severe COVID-19 after a successfully treated tuberculosis without persistent lung damage is probably not increased. However, if tuberculosis has led to sequelae such as bronchiectasis, fibrosis, or COPD [111, 112], an increased risk of severe COVID-19 cannot be excluded (see also answers to questions 1, 4, 5, and 6 of this statement). Published data suggest a more severe COVID-19 course in patients infected with SARSCoV-2 during active tuberculosis [113-115]. However, due to the small number of published cases, we are not yet in a position to provide a definite statement. In addition, comorbidities need to be taken into consideration [116]. For the success of tuberculosis therapy, it is of utmost im- 
portance that patients keep all necessary doctor's appointments and avoid therapy interruptions, despite the challenges of the current pandemic [117]. Therefore, both the German Central Committee against Tuberculosis (DZK) [118], and the WHO (https://www.who.int/ teams/global-tuberculosis-programme/covid-19) strongly recommend that all possible effort should be made to maintain tuberculosis services in the context of the SARS-CoV-2 pandemic. Epidemiological data have led to the hypothesis that vaccination against tuberculosis (BCG) may protect against SARS-CoV-2 infections and severe disease [119-121]. Heterologous protective effects against other virus infections have been described [122]. However, whether these can also be assumed for SARS$\mathrm{CoV}-2$ has not yet been proven and is currently being investigated in randomized trials.

\section{Question 13 (pulmonary embolism): I am 61 years old, not overweight, and have always been a nonsmoker. Three years ago, I was diagnosed with a pulmonary embolism. No trigger or genetic cause was identified. Until 2 years ago, I took an anticoagulant; I have not had another pulmonary embolism since then. I read that coronavirus infection can cause pulmonary embolisms. Am I at a higher risk for severe COVID-19? Should I take the anticoagulant again, just in case?}

Answer 13: COVID-19 is associated with a significantly increased risk of thrombosis and pulmonary embolism [10, 11, 123-125]. Laboratory parameters (such as elevated d-dimers), which indicate a risk to develop blood clots as a result of the strong inflammatory response, were seen in over $50 \%$ of cases $[4,126]$. The percentage of patients with confirmed pulmonary embolism, deep vein thrombosis, and/or microembolisms with subsequent organ dysfunction (e.g., of the kidneys, heart, central nervous system) is also high and on average 25\% [127-129] (probably even higher [125]), although the data obtained until now were obtained without a control group and are therefore not very robust. The mortality rate of hospitalized COVID-19 patients could be significantly reduced by early thromboprophylaxis [130]. Prophylactic anticoagulation is currently recommended for all hospitalized COVID-19 patients, irrespective of a history of thrombosis or embolism. In contrast, therapeutic anticoagulation is indicated in confirmed thrombosis/embolism and, in certain situations, in COVID-19 patients in intensive care (e.g., ECMO). An administration of semi-therapeutic

Risk Assessment in the SARS-CoV-2 Pandemic doses of low-molecular heparin or even full anticoagulation may be considered for ICU patients depending on the clinical severity and procoagulatory activity (e.g., significantly elevated or increasing d-dimers) [131-133]. According to currently available information, patients with a history of thrombosis or pulmonary embolism, who are generally at risk of recurrence, do not appear to have an increased risk of thrombosis in the context of COVID-19 compared to the general population. Consequently, there is no indication for routine prophylactic antithrombotic treatment in COVID-19 patients managed at home. Patients with a history of pulmonary embolism who are no longer taking anticoagulants should generally and especially during the COVID-19 epidemic, follow the general precautions such as avoiding extended immobilization and ensuring adequate fluid intake. When presenting with suspected COVID-19 symptoms to their primary care physician or the emergency department of a hospital, it is of utmost importance that patients mention their history of pulmonary embolism or venous thrombosis. This will ensure that thrombosis prophylaxis is initiated without delay as soon as the COVID-19 suspicion has been confirmed and the patient is hospitalized $[134,135]$.

\section{Conclusion}

We would like to reiterate that patients with chronic respiratory diseases should generally observe the RKI recommendations (AHA-L rules of physical distancing and hygiene) and follow the vaccination recommendations (www.rki.de). With the start of the second lockdown in Germany in November 2020, the German sports association for disabled people (DBS) and the German Airways League (DAL) initially recommended the temporary suspension of all sports-based rehabilitation, including outpatient breathing exercises for groups [136]. As long as distancing rules, hygiene rules, and patients' current symptoms are strictly observed (no participation of patients with any acute symptoms), exercises for people with chronic respiratory conditions in small groups are currently permitted in many of the federal states of Germany. Since the regulations of the federal states and regional health authorities in Germany may change at short notice, it is advisable to inquire with local authorities, especially health authorities, whether rehabilitation measures in small groups are permitted. If this is not the case, patients should continue to exercise at home. Group training with structured training programs (e.g., NASA, CO- 
BRA) that are conducted at medical offices should not take place at the moment. However, the owners of such practices can offer customized instruction (at least in inhalation techniques) and refer to future training dates. The DAL is currently developing Internet-based training programs and offers comprehensive information for patients as well as training videos on inhalation techniques (www.atemwegsliga.de). Concerning the question of the clinical management of COVID-19, comprehensive, separate statements are available from both the DGP [137] and the RKI [133].

\section{Acknowledgement}

The authors are indebted to Mrs. Gunda Mundt for expert translational service.

\section{Conflict of Interest Statement}

The authors have no conflicts of interest to declare.

\section{Funding Sources}

German Respiratory Society (DGP e.V.).

\section{Author Contributions}

All authors corrected the initial draft of the manuscript. The authors wrote specific initial drafts of the manuscripts: M.L., M.Ko., T.S., T.W., T.B.: General part; M.L., K.F.R., C.T., M.J.: Asthma parts; M.Kr., H.W., T.G.B.: sarcoidosis and ILD; H.G.-F., R.O.-K., B.H.: tuberculosis; F.C.R.: CF; C.F.V.: COPD; N.R., M.R.: lung cancer; J.G.: lung transplantation; S.K., J.M.: pulmonary embolism; W.W.: neuromuscular diseases and sleep apnea; H.W.: pulmonary rehabilitation, exercise and patient education.

\section{References}

1 Buitrago-Garcia D, Egli-Gany D, Counotte MJ, Hossmann S, Imeri H, Ipekci AM, et al. Occurrence and transmission potential of asymptomatic and presymptomatic SARSCoV-2 infections: a living systematic review and meta-analysis. PLoS Med. 2020 Sep; 17(9):e1003346.

2 Robert-Koch-Institut (RKI). 2021. Available from: https://www.rki.de/DE/Content/InfAZ/ N/Neuartiges_Coronavirus/Situationsberichte/ Feb_2021/Archiv_Feb_2021html.

3 He X, Lau EHY, Wu P, Deng X, Wang J, Hao $\mathrm{X}$, et al. Temporal dynamics in viral shedding and transmissibility of COVID-19. Nat Med. 2020 May;26(5):672-5.

4 Berlin DA, Gulick RM, Martinez FJ. Severe Covid-19. N Engl J Med. 2020 Dec 17;383(25): 2451-60.

5 Gandhi RT, Lynch JB, Del Rio C. Mild or moderate Covid-19. N Engl J Med. 2020 Oct 29;383(18):1757-66.

6 Karagiannidis C, Mostert C, Hentschker C, Voshaar T, Malzahn J, Schillinger G, et al. Case characteristics, resource use, and outcomes of 10021 patients with COVID-19 admitted to 920 German hospitals: an observational study. Lancet Respir Med. 2020 Sep; 8(9):853-62.

7 Kluge S, Janssens U, Welte T, Weber-Carstens S, Schälte G, Salzberger B, et al. [German recommendations for treatment of critically ill patients with COVID-19-version 3: S1-guideline]. Anaesthesist. 2020 Sep;69(9):653-64.

8 Windisch W, Weber-Carstens S, Kluge S, Rossaint R, Welte T, Karagiannidis C. Invasive and non-invasive ventilation in patients with COVID-19. Dtsch Arztebl Int. 2020 Aug 3;117(31-32):528-33.
9 Ackermann M, Verleden SE, Kuehnel M, Haverich A, Welte T, Laenger F, et al. Pulmonary vascular endothelialitis, thrombosis, and angiogenesis in Covid-19. N Engl J Med. 2020 Jul 9;383(2):120-8.

10 Bilaloglu S, Aphinyanaphongs Y, Jones S, Iturrate E, Hochman J, Berger JS. Thrombosis in hospitalized patients with COVID-19 in a New York City health system. JAMA. 2020 Aug 25;324(8):799-801.

11 Nicolai L, Leunig A, Brambs S, Kaiser R, Weinberger $\mathrm{T}$, Weigand $\mathrm{M}$, et al. Immunothrombotic dysregulation in COVID-19 pneumonia is associated with respiratory failure and coagulopathy. Circulation. $2020 \mathrm{Sep}$ 22;142(12):1176-89.

12 Sokolowska M, Lukasik ZM, Agache I, Akdis CA, Akdis D, Akdis M, et al. Immunology of COVID-19: mechanisms, clinical outcome, diagnostics, and perspectives-A report of the European Academy of Allergy and Clinical Immunology (EAACI). Allergy. 2020 Oct; 75(10):2445-76.

13 Kolditz M, Tesch F, Mocke L, Höffken G, Ewig S, Schmitt J. Burden and risk factors of ambulatory or hospitalized CAP: a population based cohort study. Respir Med. 2016 Dec;121:32-8.

14 Gudbjartsson DF, Norddahl GL, Melsted P, Gunnarsdottir K, Holm H, Eythorsson E, et al. Humoral immune response to SARSCoV-2 in Iceland. N Engl J Med. 2020 Oct 29; 383(18):1724-34.

15 Pastor-Barriuso R, Pérez-Gómez B, Hernán MA, Pérez-Olmeda M, Yotti R, Oteo-Iglesias $\mathrm{J}$, et al. Infection fatality risk for SARS-CoV-2 in community dwelling population of Spain: nationwide seroepidemiological study. BMJ. 2020 Nov 27;371:m4509.
16 Salje H, Tran Kiem C, Lefrancq N, Courtejoie N, Bosetti P, Paireau J, et al. Erratum for the report: "Estimating the burden of SARSCoV-2 in France," by H. Salje, C. Tran Kiem, N. Lefrancq, N. Courtejoie, P. Bosetti, J. Paireau, A. Andronico, N. Hozé, J. Richet, C.L. Dubost, Y. Le Strat, J. Lessler, D. LevyBruhl, A. Fontanet, L. Opatowski, P.-Y. Boelle, S. Cauchemez. Science. 2020 Jul 10; 368(6500):208-11.

17 Ward H, Atchison C, Whitaker M, Ainslie KEC, Elliott J, Okell L, et al. SARS-CoV-2 antibody prevalence in England following the first peak of the pandemic. Nat Commun. 2021 Feb 10;12(1):905.

18 Rajgor DD, Lee MH, Archuleta S, Bagdasarian N, Quek SC. The many estimates of the COVID-19 case fatality rate. Lancet Infect Dis. 2020 Jul;20(7):776-7.

19 Williamson EJ, Walker AJ, Bhaskaran K, Bacon S, Bates C, Morton CE, et al. Factors associated with COVID-19-related death using OpenSAFELY. Nature. 2020 Aug;584(7821): 430-6.

20 Chen R, Liang W, Jiang M, Guan W, Zhan C, Wang T, et al. Risk factors of fatal outcome in hospitalized subjects with coronavirus disease 2019 from a nationwide analysis in China. Chest. 2020 Jul;158(1):97-105.

21 Clift AK, Coupland CAC, Keogh RH, DiazOrdaz K, Williamson E, Harrison EM, et al. Living risk prediction algorithm (QCOVID) for risk of hospital admission and mortality from coronavirus 19 in adults: national derivation and validation cohort study. BMJ. 2020 Oct 20;371:m3731. 
22 Docherty AB, Harrison EM, Green CA, Hardwick HE, Pius R, Norman L, et al. Features of 20133 UK patients in hospital with covid-19 using the ISARIC WHO clinical characterisation protocol: prospective observational cohort study. BMJ. 2020 May 22;369:m1985.

23 Knight SR, Ho A, Pius R, Buchan I, Carson G, Drake TM, et al. Risk stratification of patients admitted to hospital with covid-19 using the ISARIC WHO clinical characterisation protocol: development and validation of the $4 \mathrm{C}$ mortality score. BMJ. 2020 Sep 9;370:m3339.

24 Nachtigall I, Lenga P, Jóźwiak K, Thürmann P, Meier-Hellmann A, Kuhlen R, et al. Clinical course and factors associated with outcomes among 1904 patients hospitalized with COVID-19 in Germany: an observational study. Clin Microbiol Infect. 2020 Dec;26(12):1663-9.

25 Petrilli CM, Jones SA, Yang J, Rajagopalan H, O'Donnell L, Chernyak Y, et al. Factors associated with hospital admission and critical illness among 5279 people with coronavirus disease 2019 in New York City: prospective cohort study. BMJ. 2020 May 22;369:m1966.

26 Zádori N, Váncsa S, Farkas N, Hegyi P, Erőss $B$. The negative impact of comorbidities on the disease course of COVID-19. Intensive Care Med. 2020 Sep;46(9):1784-6.

27 Richardson S, Hirsch JS, Narasimhan M, Crawford JM, McGinn T, Davidson KW, et al. Presenting characteristics, comorbidities, and outcomes among 5700 patients hospitalized with COVID-19 in the New York City area. JAMA. 2020 May 26;323(20):2052-9.

28 Arons MM, Hatfield KM, Reddy SC, Kimball A, James A, Jacobs JR, et al. Presymptomatic SARS-CoV-2 infections and transmission in a skilled nursing facility. N Engl J Med. 2020 May 28;382(22):2081-90.

29 Izquierdo JL, Almonacid C, González Y, Del Rio-Bermúdez C, Ancochea J, Cárdenas R, et al. The impact of COVID-19 on patients with asthma. Eur Respir J. 2021 Mar 4;57(3): 2003142.

30 Calmes D, Graff S, Maes N, Frix AN, Thys M, Bonhomme O, et al. Asthma and COPD Are not risk factors for ICU stay and death in case of SARS-CoV2 infection. J Allergy Clin Immunol Pract. 2021 Jan;9(1):160-9.

31 Grandbastien M, Piotin A, Godet J, AbessoloAmougou I, Ederlé C, Enache I, et al. SARS$\mathrm{CoV}-2$ pneumonia in hospitalized asthmatic patients did not induce severe exacerbation. J Allergy Clin Immunol Pract. 2020 Sep;8(8): 2600-7.

32 Santos MM, Lucena EES, Lima KC, Brito AAC, Bay MB, Bonfada D. Survival and predictors of deaths of patients hospitalised due to COVID-19 from a retrospective and multicentre cohort study in Brazil. Epidemiol Infect. 2020 Sep 7;148:e198.

33 Avdeev S, Moiseev S, Brovko M, Yavorovskiy A, Umbetova K, Akulkina L, et al. Low prevalence of bronchial asthma and chronic obstructive lung disease among intensive care unit patients with COVID-19. Allergy. 2020 Oct;75(10):2703-4.
34 Abe K, Miyawaki A, Nakamura M, Ninomiya $\mathrm{H}$, Kobayashi Y. Trends in hospitalizations for asthma during the COVID-19 outbreak in Japan. J Allergy Clin Immunol Pract. 2021 Jan;9(1):494-6.e1.

35 Chhiba KD, Patel GB, Vu THT, Chen MM, Guo A, Kudlaty E, et al. Prevalence and characterization of asthma in hospitalized and nonhospitalized patients with COVID-19. J Allergy Clin Immunol. 2020 Aug;146(2):30714.e4.

36 Lieberman-Cribbin W, Rapp J, Alpert N, Tuminello S, Taioli E. The impact of asthma on mortality in patients with COVID-19. Chest. 2020 Dec;158(6):2290-1.

37 Lovinsky-Desir S, Deshpande DR, De A, Murray L, Stingone JA, Chan A, et al. Asthma among hospitalized patients with COVID-19 and related outcomes. J Allergy Clin Immunol. 2020 Nov;146(5):1027-34.e4.

38 Robinson LB, Fu X, Bassett IV, Triant VA, Foulkes AS, Zhang Y, et al. COVID-19 severity in hospitalized patients with asthma: a matched cohort study. The Journal of Allergy and Clinical Immunology In practice. 2021 Jan;9(1):497-500.

39 Rosenthal JA, Awan SF, Fintzi J, Keswani A, Ein D. Asthma is associated with increased risk of intubation but not hospitalization or death in COVID-19. Ann Allergy Asthma Immunol. 2021 Jan;126(1):93-5.

40 Wang L, Foer D, Bates DW, Boyce JA, Zhou L. Risk factors for hospitalization, intensive care, and mortality among patients with asthma and COVID-19. J Allergy Clin Immunol. 2020 Oct;146(4):808-12.

41 Broadhurst R, Peterson R, Wisnivesky JP, Federman A, Zimmer SM, Sharma S, et al. Asthma in COVID-19 hospitalizations: an overestimated risk factor? Ann Am Thorac Soc. 2020 Dec;17(12):1645-8.

42 Antonicelli L, Tontini C, Manzotti G, Ronchi L, Vaghi A, Bini F, et al. Severe asthma in adults does not significantly affect the outcome of COVID-19 disease: results from the Italian severe asthma registry. Allergy. 2021 Mar;76(3):902-5.

43 Bhalla A, Mukherjee M, Radford K, Nazy I, Kjarsgaard M, Bowdish DME, et al. Dupilum$\mathrm{ab}$, severe asthma airway responses, and SARS-CoV-2 serology. Allergy. 2021 Mar; 76(3):957-8.

44 Förster-Ruhrmann U, Szczepek AJ, Bachert C, Olze H. COVID-19 in a patient with severe chronic rhinosinusitis with nasal polyps during therapy with dupilumab. J Allergy Clin Immunol. 2020 Jul;146(1):218-20.e2.

45 Hanon S, Brusselle G, Deschampheleire M, Louis R, Michils A, Peché R, et al. COVID-19 and biologics in severe asthma: data from the Belgian severe asthma registry. Eur Respir J. 2020 Dec;56(6):2002857.
46 Haroun-Díaz E, Vázquez de la Torre M, Ruano FJ, Somoza Álvarez ML, Alzate DP, González PL, et al. Severe asthma during the COVID-19 pandemic: clinical observations. J Allergy Clin Immunol Pract. 2020 Sep;8(8): 2787-9.

47 Lommatzsch M, Stoll P, Virchow JC. COVID-19 in a patient with severe asthma treated with Omalizumab. Allergy. 2020 Oct; 75(10):2705-8

48 Matucci A, Caminati M, Vivarelli E, Vianello A, Micheletto C, Menzella F, et al. COVID-19 in severe asthmatic patients during ongoing treatment with biologicals targeting type 2 inflammation: results from a multicenter Italian survey. Allergy. 2021 Mar;76(3):871-4.

49 Renner A, Marth K, Patocka K, Pohl W. COVID-19 in a severe eosinophilic asthmatic receiving benralizumab: a case study. J Asthma. 2021 Sep;58(9):1270-2.

50 Yang JM, Koh HY, Moon SY, Yoo IK, Ha EK, You S, et al. Allergic disorders and susceptibility to and severity of COVID-19: a nationwide cohort study. J Allergy Clin Immunol. 2020 Oct;146(4):790-8.

51 Choi YJ, Park JY, Lee HS, Suh J, Song JY, Byun $\mathrm{MK}$, et al. Effect of asthma and asthma medication on the prognosis of patients with COVID-19. Eur Respir J. 2021 Mar 4;57(3): 2002226

52 Wang Y, Ao G, Qi X, Xie B. The association between COVID-19 and asthma: a systematic review and meta-analysis. Clin Exp Allergy. 2020 Nov;50(11):1274-7.

53 Farne H, Singanayagam A. Why asthma might surprisingly protect against poor outcomes in COVID-19. Eur Respir J. 2020 Dec 10;56(6):2003045.

54 Keswani A, Dhana K, Rosenthal JA, Moore D, Mahdavinia M. Atopy is predictive of a decreased need for hospitalization for coronavirus disease 2019. Ann Allergy Asthma Immunol. 2020 Oct;125(4):479-81.

55 Yao Y, Wang H, Liu Z. Expression of ACE2 in airways: implication for COVID-19 risk and disease management in patients with chronic inflammatory respiratory diseases. Clin Exp Allergy. 2020 Dec;50(12):1313-24.

56 Matusiak M, Schürch CM. Expression of SARS-CoV-2 entry receptors in the respiratory tract of healthy individuals, smokers and asthmatics. Respir Res. 2020 Sep 29;21(1):252.

57 Bradding P, Richardson M, Hinks TSC, Howarth PH, Choy DF, Arron JR, et al. ACE2, TMPRSS2, and furin gene expression in the airways of people with asthma-implications for COVID-19. J Allergy Clin Immunol. 2020 Jul; 146(1):208-11.

58 Camiolo M, Gauthier M, Kaminski N, Ray A, Wenzel SE. Expression of SARS-CoV-2 receptor ACE2 and coincident host response signature varies by asthma inflammatory phenotype. J Allergy Clin Immunol. 2020 Aug; 146(2):315-24.e7.
Risk Assessment in the SARS-CoV-2 Pandemic
Respiration 2022;101:307-320

DOI: $10.1159 / 000518896$ 
59 Hegde S. Does asthma make COVID-19 worse? Nat Rev Immunol. 2020 Apr 28;1. Epub ahead of print.

60 Kimura H, Francisco D, Conway M, Martinez FD, Vercelli D, Polverino F, et al. Type 2 inflammation modulates ACE2 and TMPRSS2 in airway epithelial cells. J Allergy Clin Immunol. 2020 Jul;146(1):80-8.e8.

61 Schultze A, Walker AJ, MacKenna B, Morton $\mathrm{CE}$, Bhaskaran K, Brown JP, et al. Risk of COVID-19-related death among patients with chronic obstructive pulmonary disease or asthma prescribed inhaled corticosteroids: an observational cohort study using the OpenSAFELY platform. Lancet Respir Med. 2020 Nov;8(11):1106-20.

62 Peters MC, Sajuthi S, Deford P, Christenson $\mathrm{S}$, Rios CL, Montgomery MT, et al. COVID-19 related genes in sputum cells in asthma: relationship to demographic features and corticosteroids. Am J Respir Crit Care Med. 2020 Jul 1;202(1):83-90.

63 Maes T, Bracke K, Brusselle GG. COVID-19, Asthma, and Inhaled Corticosteroids (ICS): another beneficial effect of ICS? Am J Respir Crit Care Med. 2020 Jul 1;202(1):8-10.

64 Klimek L, Jutel M, Akdis C, Bousquet J, Akdis $\mathrm{M}$, Bachert $\mathrm{C}$, et al. Handling of allergen immunotherapy in the COVID-19 pandemic: an ARIA-EAACI statement. Allergy. 2020 Jul; 75(7):1546-54.

65 Carugno A, Gambini DM, Raponi F, Vezzoli P, Locatelli AGC, Di Mercurio M, et al. COVID-19 and biologics for psoriasis: a high-epidemic area experience: Bergamo, Lombardy, Italy. J Am Acad Dermatol. 2020 Jul;83(1): 292-4.

66 Monti S, Balduzzi S, Delvino P, Bellis E, Quadrelli VS, Montecucco C. Clinical course of COVID-19 in a series of patients with chronic arthritis treated with immunosuppressive targeted therapies. Ann Rheum Dis. 2020 May;79(5):667-8.

67 Maijers I, Kearns N, Harper J, Weatherall M, Beasley R. Oral steroid-sparing effect of highdose inhaled corticosteroids in asthma. Eur Respir J. 2020 Jan;55(1):1901147.

68 Alqahtani JS, Oyelade T, Aldhahir AM, Alghamdi SM, Almehmadi M, Alqahtani AS, et al. Prevalence, severity and mortality associated with COPD and smoking in patients with COVID-19: a rapid systematic review and meta-analysis. PLoS One. 2020;15(5): e0233147.

69 Peng Y, Meng K, He M, Zhu R, Guan H, Ke Z, et al. Clinical characteristics and prognosis of 244 cardiovascular patients suffering from coronavirus disease in Wuhan, China. J Am Heart Assoc. 2020 Oct 20;9(19):e016796.

70 Fosbøl EL, Butt JH, Østergaard L, Andersson C, Selmer C, Kragholm K, et al. Association of Angiotensin-converting enzyme inhibitor or angiotensin receptor blocker use with $\mathrm{CO}$ VID-19 diagnosis and mortality. JAMA. 2020 Jul 14;324(2):168-77.
71 Zhang P, Zhu L, Cai J, Lei F, Qin JJ, Wang Y, et al. Response by Zhang et al to letter regarding article, "association of inpatient use of angiotensin-converting enzyme inhibitors and angiotensin II receptor blockers with mortality among patients with hypertension hospitalized with COVID-19". Circ Res. 2020 Jun 5;126(12):e142-81.

72 Colombo C, Burgel PR, Gartner S, van Koningsbruggen-Rietschel S, Naehrlich L, Sermet-Gaudelus I, et al. Impact of COVID-19 on people with cystic fibrosis. Lancet Respir Med. 2020 May;8(5):e35-6.

73 McClenaghan E, Cosgriff R, Brownlee K, Ahern S, Burgel PR, Byrnes CA, et al. The global impact of SARS-CoV-2 in 181 people with cystic fibrosis. J Cyst Fibros. 2020 Nov 4; 19(6):868-71

74 Hellmuth T, Hoppe D, Teschler S, Hoheisel R, Hillmann T. [Recommendations of the German Respiratory Society (DGP) on hygiene measures during treatment of patients with lung diseases in the outpatient physiotherapy practice in times of the SARS-CoV-2 pandemic]. Pneumologie. 2021 Jan;75(1):57-9.

75 Ringshausen FC, Hellmuth T, Dittrich AM. [Evidence-based treatment of cystic fibrosis]. Internist. 2020 Dec;61(12):1212-29.

76 Griese M, Costa S, Linnemann RW, Mall MA McKone EF, Polineni D, et al. Safety and efficacy of elexacaftor/tezacaftor/ivacaftor for $\geq 24$ weeks in people with CF and $\geq 1$ F508del allele: interim results of an open-label phase three clinical trial. Am J Respir Crit Care Med. 2021 Feb 1;203(3):381-5.

77 Drake TM, Docherty AB, Harrison EM, Quint JK, Adamali H, Agnew S, et al. Outcome of hospitalization for COVID-19 in patients with interstitial lung disease: an international multicenter study. Am J Respir Crit Care Med. 2020 Dec 15;202(12):1651-65.

78 Sweiss NJ, Korsten P, Syed HJ, Syed A, Baughman RP, Yee AMF, et al. When the game changes: guidance to adjust sarcoidosis management during the coronavirus disease 2019 pandemic. Chest. 2020 Sep;158(3):892-5.

79 George PM, Wells AU, Jenkins RG. Pulmonary fibrosis and COVID-19: the potential role for antifibrotic therapy. Lancet Respir Med. 2020 Aug;8(8):807-15.

80 Morgenthau AS, Levin MA, Freeman R, Reich DL, Klang E. Moderate or severe impairment in pulmonary function is associated with mortality in sarcoidosis patients infected with SARS-CoV-2. Lung. 2020 Oct;198(5):771-5.

81 Gianfrancesco M, Hyrich KL, Al-Adely S, Carmona L, Danila MI, Gossec L, et al. Characteristics associated with hospitalisation for COVID-19 in people with rheumatic disease: data from the COVID-19 Global Rheumatology Alliance physician-reported registry. Ann Rheum Dis. 2020 Jul;79(7):859-66.
82 Gianfrancesco M, Hyrich KL, Yazdany J, Machado PM, Robinson PC. Response to: "Glucocorticoid-induced relapse of $\mathrm{CO}$ VID-19 in a patient with sarcoidosis" by Györfi et al. Ann Rheum Dis. 2020 Jun 30. Epub ahead of print.

83 Kiani A, Razavi F, Bandegani N, Farahani M, Abedini A. Investigation of sarcoidosis patients during COVID-19 pandemic. Sarcoidosis Vasc Diffuse Lung Dis. 2020;37(4): e2020015.

84 Manansala M, Ascoli C, Alburquerque AG, Perkins D, Mirsaedi M, Finn P, et al. Case series: COVID-19 in African American patients with sarcoidosis. Front Med. 2020;7:588527.

85 Baughman RP, Lower EE, Buchanan M, Rottoli P, Drent M, Sellares J, et al. Risk and outcome of COVID-19 infection in sarcoidosis patients: results of a self-reporting questionnaire. Sarcoidosis Vasc Diffuse Lung Dis. 2020;37(4):e2020009.

86 Conticini E, Bargagli E, Bardelli M, Rana GD, Baldi C, Cameli P, et al. COVID-19 pneumonia in a large cohort of patients treated with biological and targeted synthetic antirheumatic drugs. Ann Rheum Dis. 2021 Feb;80(2): e14.

87 Landewé RB, Machado PM, Kroon F, Bijlsma HW, Burmester GR, Carmona L, et al. EULAR provisional recommendations for the management of rheumatic and musculoskeletal diseases in the context of SARS-CoV-2. Ann Rheum Dis. 2020 Jul;79(7):851-8.

88 Aigner C, Dittmer U, Kamler M, Collaud S, Taube C. COVID-19 in a lung transplant recipient. J Heart Lung Transplant. 2020 Jun; 39(6):610-1.

89 Kates OS, Haydel BM, Florman SS, Rana MM, Chaudhry ZS, Ramesh MS, et al. COVID-19 in solid organ transplant: a multi-center cohort study. Clin Infect Dis. 2020 Aug 7. Epub ahead of print.

90 Akalin E, Azzi Y, Bartash R, Seethamraju H, Parides M, Hemmige V, et al. Covid-19 and kidney transplantation. N Engl J Med. 2020 Jun 18;382(25):2475-77.

91 Fernandez-Ruiz M, Andres A, Loinaz C, Delgado JF, Lopez-Medrano F, San Juan R, et al. COVID-19 in solid organ transplant recipients: a single-center case series from Spain. Am J Transplant. 2020 Jul;20(7):1849-58.

92 Latif F, Farr MA, Clerkin KJ, Habal MV, Takeda K, Naka Y, et al. Characteristics and outcomes of recipients of heart transplant with coronavirus disease 2019. JAMA Cardiol. 2020 Oct 1;5(10):1165-69.

93 Albiges L, Foulon S, Bayle A, Gachot B, Pommeret F, Willekens C, et al. Determinants of the outcomes of patients with cancer infected with SARS-CoV-2: results from the Gustave Roussy cohort. Nat Cancer. 2020 2020/10/01; 1(10):965-75.

94 Kuderer NM, Choueiri TK, Shah DP, Shyr Y, Rubinstein SM, Rivera DR, et al. Clinical impact of COVID-19 on patients with cancer (CCC19): a cohort study. Lancet. 2020 Jun 20; 395(10241):1907-18. 
95 Liang W, Guan W, Chen R, Wang W, Li J, $\mathrm{Xu} \mathrm{K}$, et al. Cancer patients in SARS-CoV-2 infection: a nationwide analysis in China. Lancet Oncol. 2020 Mar;21(3):335-7.

96 Rugge M, Zorzi M, Guzzinati S. SARSCoV-2 infection in the Italian Veneto region: adverse outcomes in patients with cancer. Nat Cancer. 2020 Aug 1;1(8):784-8.

97 Subbiah V. A global effort to understand the riddles of COVID-19 and cancer. Nat Cancer. 2020 2020/10/01;1(10):943-5.

98 Tian J, Yuan X, Xiao J, Zhong Q, Yang C, Liu $\mathrm{B}$, et al. Clinical characteristics and risk factors associated with COVID-19 disease severity in patients with cancer in Wuhan, China: a multicentre, retrospective, cohort study. Lancet Oncol. 2020 Jul;21(7):893-903.

99 Garassino MC, Whisenant JG, Huang LC, Trama A, Torri V, Agustoni F, et al. COVID-19 in patients with thoracic malignancies (TERAVOLT): first results of an international, registry-based, cohort study. Lancet Oncol. 2020 Jul;21(7):914-22.

100 Whisenant JG, Trama A, Torri V, De Toma A, Viscardi G, Cortellini A, et al. TERAVOLT: Thoracic Cancers International COVID-19 Collaboration. Cancer Cell. 2020 Jun 8;37(6):742-5.

101 Baena Espinar J, Torri V, Whisenant J, Hirsch FR, Rogado J, de Castro Carpeño J, et al. LBA75 defining COVID-19 outcomes in thoracic cancer patients: TERAVOLT (Thoracic cancERs international coVid 19 cOLlaboraTion). Ann Oncol. 2020;31:S1204-5.

102 Horn L, Whisenant JG, Torri V, Huang L-C, Trama A, Paz-Ares LG, et al. Thoracic Cancers International COVID-19 Collaboration (TERAVOLT): impact of type of cancer therapy and COVID therapy on survival. J Clin Oncol. 2020;38(Suppl 18l):LBA111.

103 Luo J, Rizvi H, Preeshagul IR, Egger JV, Hoyos D, Bandlamudi C, et al. COVID-19 in patients with lung cancer. Ann Oncol. 2020 Oct;31(10):1386-96.

104 Sereno M, Gutierrez-Gutierrez G, Sandoval C, Falagan S, Jimenez-Gordo AM, Merino $\mathrm{M}$, et al. A favorable outcome of pneumonia COVID 19 in an advanced lung cancer patient with severe neutropenia: Is immunosuppression a risk factor for SARS-COV2 infection? Lung Cancer. 2020 Jul;145:213-5.

105 Calabro L, Peters S, Soria JC, Di Giacomo AM, Barlesi F, Covre A, et al. Challenges in lung cancer therapy during the COVID-19 pandemic. Lancet Respir Med. 2020 Jun; 8(6):542-4.

106 Curigliano G, Banerjee S, Cervantes A, Garassino MC, Garrido P, Girard N, et al. Managing cancer patients during the COVID-19 pandemic: an ESMO multidisciplinary expert consensus. Ann Oncol. 2020 Oct; 31(10):1320-35.
107 Büchner N, Woehrle H, Dellweg D, Wiater A, Young $\mathrm{P}$, Hein $\mathrm{H}$, et al. [Management of diagnostic procedures and treatment of sleep related breathing disorders in the context of the coronavirus pandemic]. Somnologie. 2020 Jun 22. Epub ahead of print.

108 Pfeifer M, Ewig S, Voshaar T, Randerath WJ, Bauer T, Geiseler J, et al. Position paper for the state-of-the-art application of respiratory support in patients with COVID-19. Respiration. 2020;99(6):521-42.

109 Windisch W, Dellweg D, Geiseler J, Westhoff M, Pfeifer M, Suchi S, et al. Prolonged weaning from mechanical ventilation: results from specialized weaning centers. Dtsch Arztebl Int. 2020;117:197-204.

110 Bajwah S, Wilcock A, Towers R, Costantini M, Bausewein C, Simon ST, et al. Managing the supportive care needs of those affected by COVID-19. Eur Respir J. 2020 Apr 23; 55(4):2000815.

111 Ravimohan S, Kornfeld H, Weissman D, Bisson GP. Tuberculosis and lung damage: from epidemiology to pathophysiology. Eur Respir Rev. 2018 Mar 31;27(147):27.

112 Gupte AN, Paradkar M, Selvaraju S, Thiruvengadam K, Shivakumar SVBY, Sekar K, et al. Assessment of lung function in successfully treated tuberculosis reveals high burden of ventilatory defects and COPD. PLoS One. 2019;14(5): $\mathrm{e} 0217289$.

113 Gupta N, Ish P, Gupta A, Malhotra N, Caminero JA, Singla R, et al. A profile of a retrospective cohort of 22 patients with $\mathrm{CO}$ VID-19 and active/treated tuberculosis. Eur Respir J. 2020 Nov;56(5):2003408.

114 Tadolini M, Codecasa LR, García-García JM, Blanc FX, Borisov S, Alffenaar JW, et al. Active tuberculosis, sequelae and COVID-19 co-infection: first cohort of 49 cases. Eur Respir J. 2020 Jul;56(1):2001398.

115 Tamuzi JL, Ayele BT, Shumba CS, Adetokunboh OO, Uwimana-Nicol J, Haile ZT, et al. Implications of COVID-19 in high burden countries for HIV/TB: A systematic review of evidence. BMC Infect Dis. 2020 Oct 9;20(1):744

116 Ong CWM, Migliori GB, Raviglione M, MacGregor-Skinner G, Sotgiu G, Alffenaar $J W$, et al. Epidemic and pandemic viral infections: impact on tuberculosis and the lung: a consensus by the World Association for Infectious Diseases and Immunological Disorders (WAidid), Global Tuberculosis Network (GTN), and members of the European Society of Clinical Microbiology and Infectious Diseases Study Group for Mycobacterial Infections (ESGMYC). Eur Respir J. 2020 Oct 1;56(4):2001727.

117 Cilloni L, Fu H, Vesga JF, Dowdy D, Pretorius C, Ahmedov S, et al. The potential impact of the COVID-19 pandemic on the tuberculosis epidemic a modelling analysis. EClinicalMedicine. 2020 Nov;28:100603.
118 Otto-Knapp R, Häcker B, Breuer C, Diel R, Kaufmann SHE, Korr G, et al. [DZK Recommendations for Tuberculosis, BCG and COVID-19 in Germany: (official abbreviation of coronavirus disease 2019 caused by the new coronavirus SARS-CoV-2)]. Pneumologie. 2020 Jul;74(7):412-6.

119 Curtis N, Sparrow A, Ghebreyesus TA, Netea MG. Considering BCG vaccination to reduce the impact of COVID-19. Lancet. 2020 May 16;395(10236):1545-6.

120 Joy M, Malavika B, Asirvatham ES, Sudarsanam TD, Jeyaseelan L. Is BCG associated with reduced incidence of COVID-19? A meta-regression of global data from 160 countries. Clin Epidemiol Glob Health. 2021 Jan-Mar;9:202-3.

121 O’Neill LAJ, Netea MG. BCG-induced trained immunity: can it offer protection against COVID-19? Nat Rev Immunol. 2020 Jun;20(6):335-7.

122 Moorlag SJCFM, Arts RJW, van Crevel R, Netea MG. Non-specific effects of BCG vaccine on viral infections. Clin Microbiol Infect. 2019 Dec;25(12):1473-8.

123 Menter T, Haslbauer JD, Nienhold R, Savic $\mathrm{S}$, Hopfer H, Deigendesch N, et al. Postmortem examination of COVID-19 patients reveals diffuse alveolar damage with severe capillary congestion and variegated findings in lungs and other organs suggesting vascular dysfunction. Histopathology. 2020 May 4;77(2):198-209.

124 Middeldorp S, Coppens M, van Haaps TF, Foppen M, Vlaar AP, Müller MCA, et al. Incidence of venous thromboembolism in hospitalized patients with COVID-19. J Thromb Haemost. 2020 Aug;18(8):1995-2002.

125 Wichmann D, Sperhake JP, Lütgehetmann M, Steurer S, Edler C, Heinemann A, et al. Autopsy Findings and Venous Thromboembolism in Patients With COVID-19: A Prospective Cohort Study. Ann Intern Med. 2020 Aug 18;173(4):268-77.

126 Zhou F, Yu T, Du R, Fan G, Liu Y, Liu Z, et al. Clinical course and risk factors for mortality of adult inpatients with COVID-19 in Wuhan, China: a retrospective cohort study. Lancet. 2020 Mar 28;395(10229):1054-62.

127 Cui S, Chen S, Li X, Liu S, Wang F. Prevalence of venous thromboembolism in patients with severe novel coronavirus pneumonia. J Thromb Haemost. 2020 Jun;18(6):1421-4.

128 Klok FA, Kruip MJHA, van der Meer NJM, Arbous MS, Gommers DAMPJ, Kant KM, et al. Incidence of thrombotic complications in critically ill ICU patients with COVID-19. Thromb Res. 2020 Jul;191:145-7.

129 Lodigiani C, Iapichino G, Carenzo L, Cecconi M, Ferrazzi P, Sebastian T, et al. Venous and arterial thromboembolic complications in COVID-19 patients admitted to an academic hospital in Milan, Italy. Thromb Res. 2020 Jul;191:9-14. 
130 Nadkarni GN, Lala A, Bagiella E, Chang HL, Moreno PR, Pujadas E, et al. Anticoagulation, bleeding, mortality, and pathology in hospitalized patients with COVID-19. J Am Coll Cardiol. 2020 Oct 20;76(16):1815-26.

131 European Society of Cardiology (ESC). ESC guidance for the diagnosis and management of CV disease during the COVID-19 pandemic. 2020. Available from: https://www. escardio.org/Education/COVID-19-andCardiology/ESC-COVID-19-Guidance? hit=home\&urlorig=/vgn-ext-templating.

132 Thachil J, Tang N, Gando S, Falanga A, Cattaneo $\mathrm{M}$, Levi $\mathrm{M}$, et al. ISTH interim guidance on recognition and management of coagulopathy in COVID-19. J Thromb Haemost. 2020 May;18(5):1023-6.
133 Robert-Koch-Institut (RKI). Hinweise zu Erkennung, Diagnostik und Therapie von Patienten mit COVID-19. Available from: https://pneumologie.de/fileadmin/user_upload/COVID-19/20201105_STAKOB_Covid-19_Therapie_Diagnose.pdf.

134 Bikdeli B, Madhavan MV, Jimenez D, Chuich T, Dreyfus I, Driggin E, et al. COVID-19 and thrombotic or thromboembolic disease: implications for prevention, antithrombotic therapy, and follow-up: JACC state-of-theart review. J Am Coll Cardiol. 2020 Jun 16; 75(23):2950-73.
135 Gerotziafas GT, Catalano M, Colgan MP, Pecsvarady Z, Wautrecht JC, Fazeli B, et al. Guidance for the management of patients with vascular disease or cardiovascular risk factors and COVID-19: position paper from VAS-European Independent Foundation in angiology/vascular medicine. Thromb Haemost. 2020 Dec;120(12):1597-628.

136 Worth H, Bock R, Frisch M, Göhl O, Grünig E, Glöckl R, et al. [Group training of patients with chronic lung diseases under outpatient conditions: recommendations of the Working Group Lung Sports in Germany and the German Airways League]. Pneumologie. 2021 Jan;75(1):44-56.

137 Pfeifer M, Ewig S, Voshaar T, Randerath W, Bauer T, Geiseler J, et al. [Position paper for the state of the art application of respiratory support in patients with COVID-19: German Respiratory Society]. Pneumologie. 2020 Jun;74(6):337-57. 